\title{
Patent Medicine Vendors in Rural Areas of Lagos Nigeria: Compliance with Regulatory Guidelines and Implications for Malaria Control
}

\author{
Abisoye S Oyeyemi ${ }^{1^{*}}$, Babatunde E Ogunnowo ${ }^{2}$ and Oluwakemi O Odukoya ${ }^{2}$ \\ ${ }^{1}$ Department of Community Medicine, Faculty of Clinical Sciences, College of Health Sciences, Niger Delta University, \\ Wilberforce Island, Bayelsa State, ${ }^{2}$ Department of Community Health and Primary Care, College of Medicine, University of \\ Lagos, Lagos, Nigeria.
}

*For correspondence: Email: abisoyeyemi@hotmail.com; Tel: +234-8037049837

\begin{abstract}
Purpose: To determine the compliance of patent medicine vendors (PMVs) in rural areas of Lagos State, Nigeria with set guidelines to regulate their practice and its implications for malaria control. Methods: A baseline cross-sectional study was conducted as part of an intervention study in two rural local government areas (LGAs) of Lagos State Nigeria. One hundred and eighty PMVs were randomly selected and interviewed using structured questionnaire. In addition, an observational checklist was used to monitor the drug shops for compliance with regulatory guidelines. Indicators of compliance used include proportion of PMVs with valid practicing license and proportion of shops with duly registered anti-malaria drugs.

Results: Most 148 (82.2 \%) of the respondents were shop owners with 170 (94.4\%) aged $\geq 21$ years

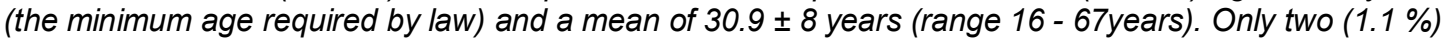
PMVs had a valid annual practicing licence and only three $(1.7 \%)$ of the drug shops had specified signposts. The shops stocked various kinds of anti-malaria drugs including those that are no longer recommended. All the sampled drugs were duly registered with NAFDAC and within expiry dates.

Conclusion: There was poor compliance with regulatory guidelines. A strict enforcement of the guidelines by the regulatory agency is recommended to ensure that only licensed persons sell appropriate anti-malaria drugs.
\end{abstract}

Keywords: Patent medicine vendors, Compliance, Guidelines, Malaria, ACTs.

\begin{abstract}
Tropical Journal of Pharmaceutical Research is indexed by Science Citation Index (SciSearch), Scopus, International Pharmaceutical Abstract, Chemical Abstracts, Embase, Index Copernicus, EBSCO, African Index Medicus, JournalSeek, Journal Citation Reports/Science Edition, Directory of Open Access Journals (DOAJ), African Journal Online, Bioline International, Open-J-Gate and Pharmacy Abstracts
\end{abstract}

\section{INTRODUCTION}

Patent Medicine Vendors (PMVs) are important informal community-based providers of health care [1-4]. Many countries, recognizing their role and contribution to ensuring equitable access by the population to essential drugs, permit them to sell certain over-the-counter (OTC) drugs, including anti-malaria drugs and other drugs for treatment of common ailments [5-7].
The activities of PMVs are usually regulated by agencies of government $[6,7]$. In Nigeria, Pharmacists Council of Nigeria (PCN) regulates PMVs' activities as established in Pharmacy Council of Nigeria Decree 91 of 1992 [8]. PCN specifies eligibility criteria for operating as a PMV, stipulates licensing requirements, and gives guidelines for operators to follow. While PCN regulates the activities of PMVs, drug registration and regulation are within the purview 
of National Agency for Food and Administration and Control (NAFDAC) [5].

Malaria remains a leading cause of morbidity and mortality in Nigeria as in other sub-Saharan Africa countries [9]. According to the new antimalarial treatment policy, trained PMVs are categorized in level 1 of malaria management [10]. At this level, a health care provider is expected to diagnose malaria symptomatically and administer artemisinin-based combination therapy (ACTs) for uncomplicated cases or give pre-referral treatment and promptly refer patients with severe febrile illness. PMVs will continue to play a major role in malaria treatment especially those in the rural areas where the burden of malaria is higher [11,12]. Not much is known about PMVs operating in the rural areas of Lagos and their level of compliance with $\mathrm{PCN}$ and NAFDAC guidelines, hence this study.

\section{METHODS}

\section{Study setting}

Lagos State is one of the 36 states of the Federal Republic of Nigeria. It is located in the southwestern zone of Nigeria and is the commercial nerve centre of the country. It is divided into 20 Local Government Areas (LGAs); 16 are classified as urban and four as rural. The rural LGAs are Ikorodu, Epe, Ibeju-Lekki and Badagry. The study was carried out in Ikorodu and Ibeju-lekki.

The Ikorodu branch of the Lagos State Medicine Dealers Association (LSMDA) had 482 registered PMVs in its four zones in the LGA and they were distributed thus: Ikorodu South (82), Ikorodu Central (75), Odogunyan (184) and Igbogbo (141). The Ibeju-Lekki branch of LSMDA had 157 registered PMVs.

There were two independent umbrella associations for PMVs in Lagos state: Lagos State Medicine Dealers' Association (LSMDA) and National Association of Patent and Proprietary Medicine Dealers (NAPPMED). We first established contact with LSMDA; it was much later while pre-testing the data collection instruments that the parallel group was discovered. We decided to limit the study to LSMDA to avoid the complexity of involving the two bodies. Lagos State Medicine Dealers' Association (LSMDA) had a branch in each LGA and for ease of administration, big LGA branches were further divided into zones. The state and the LG branches all had executive committees running the association.

\section{Study design and study population}

This was a cross-sectional study to determine the compliance with relevant regulatory guidelines by PMVs operating in rural LGAs of Lagos state. The study population comprised LSMDA-registered PMVs operating in Ikorodu (Odogunyan zone) and in Ibeju-Lekki LGAs of Lagos state. Only PMVs who had their patent medicines shops registered with the LGA branch of LSMDA were included in the study. Where the shop owner was not the one actively involved in operating a selected shop, the person in charge, either an apprentice or a sales attendant who usually sold drugs to clients, was interviewed.

\section{Sample size estimation}

The minimum sample size for the main study (intervention) was estimated using the formula for comparison of two proportions [13] and a sample size of 90 for each LGA was computed.

\section{Sampling methodology}

The proposed intervention study was designed to take place in two rural LGAs (one to serve as intervention and the other as control LGA). Using simple random sampling method by balloting, Ikorodu and Ibeju-Lekki LGAs were selected. In Ikorodu, only Odogunyan zone (the largest zone) was involved in the study. The methodological and logistic challenge of involving all the zones informed the purposive selection of Odogunyan zone where it was most certain that the required number of PMVs for Ikorodu would be obtained. Simple random sampling method was used to select 90 PMVs from each of the study areas.

\section{Ethical considerations}

Ethical approval for the study was obtained from the Research and Ethics Committee of the Lagos University Teaching Hospital. Meetings were held with the executive bodies of LSMDA at the state and LGA levels. We also attended the monthly meetings of the two LGAs and explained the purpose of the study to members. Informed consent was obtained from the respondents and they were further assured of the confidentiality of the information they would provide.

\section{Data collection and analysis}

Data were collected between July and September 2009. Executive members of LSMDA in each LGA helped to locate the selected shops and assure respondents of the association's approval. One of the authors and two trained research assistants administered the pretested 
structured questionnaire and observational checklist to respondents and their shops. The questionnaire elicited inter alia information on the socio-demographic characteristics of the PMVs and their work history. The observational checklist was used to check the shop premises, the types of antimalaria drugs in the shops, and the expiry date and registration status of the drugs. All the antimalaria drugs (AMDs) in stock for sale were identified, and one of each type of the drugs shown was arbitrarily selected by the interviewer and checked for NAFDAC number and expiry date. The Epi Info 2002 (Windows version 3.5.1) was used for data entry, cleaning, and analysis. Chi-square test (with Yates correction) and Fisher exact test were used to determine associations between qualitative variables. A $p$-value of $<0.05$ was considered statistically significant.

\section{RESULTS}

Table 1 shows that most $148(82.2 \%)$ of the respondents were shop owners. Respondents' ages ranged from 16 to 67years, with a mean age of $30.9 \pm 8$ years, and $94.4 \%$ were $\geq 21$ years (21 years is the minimum age required by PCN to be licensed to operate as a PMV [8]). The highest level of education attained by the PMVs was secondary education $144(80 \%)$. There were more females 95 (52.8\%) than males $85(47.2 \%)$ and most are married $107(59.4 \%)$. Most of the PMVs were of Igbo 85 (47.2\%) ethnic extraction and the dominant religion was Christianity 156 $(86.7 \%)$. Some significant differences exist between the two LGAs.

\section{Training and work history}

About a third $57(31.7 \%)$ of the respondents had health-related training background and majority of them were trained as auxiliary nurses. The PMVs had been in practice for a mean duration of $5.4 \pm 4.7$ years. About two-third $114(63.3 \%)$ of the PMVs mentioned attending a continuing education programme (CEP) in the previous 24 months, less than a half $75(41.7 \%)$ attended one specifically on malaria. Significantly more PMVs in lkorodu attended CEPs than their counterparts in Ibeju-Lekki. Only $10(6.3 \%)$ of shop owners claimed having a practising licence and for most of them $163(90.6 \%)$, operating their shop was their only job (Table 2).

Table 1: Socio-demographic characteristics of respondents

\begin{tabular}{|c|c|c|c|c|c|}
\hline Characteristic & $\begin{array}{l}\begin{array}{l}\text { Ikorodu } \\
(n=90)\end{array} \\
\text { Freq (\%) }\end{array}$ & $\begin{array}{l}\text { Ibeju-Lekki } \\
(n=90) \\
\text { Freq (\%) }\end{array}$ & $\begin{array}{l}\begin{array}{l}\text { Total } \\
(n=180)\end{array} \\
\text { Freq }(\%)\end{array}$ & $x^{2}$ & $P$-value \\
\hline \multicolumn{6}{|l|}{ Respondent } \\
\hline Shop owner & 78 (86.7) & $70(77.8)$ & 148 (82.2) & 4.38 & 0.112 \\
\hline Sales attendant & $6(6.7)$ & $5(5.6)$ & $11(6.1)$ & & \\
\hline Apprentice & $6(6.7)$ & $15(16.7)$ & $21(11.7)$ & & \\
\hline \multicolumn{6}{|l|}{ Age group (yrs) } \\
\hline$<21$ & $2(2.2)$ & $8(8.9)$ & $10(5.6)$ & 7.11 & 0.068 \\
\hline $21-29$ & $32(35.6)$ & $40(44.4)$ & $72(40.0)$ & & \\
\hline $30-39$ & $43(47.8)$ & $35(38.9)$ & $78(43.3)$ & & \\
\hline$\geq 40$ & $13(14.4)$ & $7(7.7)$ & $20(11.1)$ & & \\
\hline Mean age & $32.2 \pm 7.4$ & $29.6 \pm 7.9$ & $30.9 \pm 7.8$ & & \\
\hline \multicolumn{6}{|l|}{ Sex } \\
\hline Female & $58(64.4)$ & $37(41.1)$ & $95(52.8)$ & 8.92 & 0.003 \\
\hline Male & $32(35.6)$ & $53(58.9)$ & $85(47.2)$ & & \\
\hline \multicolumn{6}{|l|}{ Education } \\
\hline Primary & 7 (7.8) & $9(10.0)$ & $16(8.9)$ & 2.16 & 0.339 \\
\hline Secondary & $70(77.8)$ & 74 (82.2) & $144(80.0)$ & & \\
\hline Tertiary & $13(14.4)$ & $7(7.8)$ & $20(11.1)$ & & \\
\hline \multicolumn{6}{|l|}{ Marital status } \\
\hline Married & $68(75.6)$ & $39(43.3)$ & $107(59.4)$ & 19.38 & $<0.001$ \\
\hline Single & $22(24.4)$ & $51(56.7)$ & $73(40.6)$ & & \\
\hline \multicolumn{6}{|l|}{ Ethnic group } \\
\hline Igbo & $30(33.3)$ & $55(61.1)$ & $85(47.2)$ & 18.37 & $<0.001$ \\
\hline Yoruba & $39(43.3)$ & $30(33.3)$ & 69 (38.3) & & \\
\hline Others & $21(23.3)$ & $5(5.6)$ & $26(14.5)$ & & \\
\hline \multicolumn{6}{|l|}{ Religion } \\
\hline Christianity & $76(84.4)$ & $80(88.9)$ & $156(86.7)$ & 0.43 & 0.511 \\
\hline Islam & $14(15.6)$ & $10(11.1)$ & $24(13.3)$ & & \\
\hline
\end{tabular}


Table 2: Practice-related information and attendance of continuing education programme

\begin{tabular}{|c|c|c|c|c|c|}
\hline Variable & $\begin{array}{l}\text { Ikorodu } \\
\text { Group } \\
\text { Freq (\%) }\end{array}$ & $\begin{array}{c}\text { Ibeju- Lekki } \\
\text { Group } \\
\text { Freq (\%) }\end{array}$ & $\begin{array}{c}\text { Total } \\
\text { Freq (\%) }\end{array}$ & $x^{2}$ & $P$-value \\
\hline \multicolumn{6}{|l|}{ Previous health training } \\
\hline Yes & $33(36.7)$ & $24(26.7)$ & $57(31.7)$ & 1.64 & 0.200 \\
\hline No & $57(63.3)$ & 66 (73.3) & $123(68.3)$ & & \\
\hline Total & $90(100.0)$ & $90(100.0)$ & $180(100.0)$ & & \\
\hline \multicolumn{6}{|l|}{ Health training received } \\
\hline Auxiliary Nursing \& Others & $23(69.7)$ & $21(87.5)$ & $44(77.2)$ & 1.59 & 0.207 \\
\hline General Nursing/midwifery & $10(30.3)$ & $3(12.5)$ & $13(22.8)$ & & \\
\hline Total & $33(100.0)$ & $24(100.0)$ & $57(100.0)$ & & \\
\hline \multicolumn{6}{|l|}{ Duration of practice (yrs) } \\
\hline $1-5$ & $54(60.0)$ & $70(77.8)$ & $124(68.9)$ & 7.36 & 0.025 \\
\hline $6-10$ & $19(21.1)$ & $13(14.4)$ & $32(17.8)$ & & \\
\hline$\geq 11$ & $17(18.9)$ & $7(7.8)$ & $24(13.3)$ & & \\
\hline Total & $90(100.0)$ & $90(100.0)$ & $180(100.0)$ & & \\
\hline \multicolumn{6}{|l|}{$\begin{array}{l}\text { CEP* attendance in the last } 24 \\
\text { months }\end{array}$} \\
\hline Yes & $72(80.0)$ & $42(46.7)$ & $114(63.3)$ & 20.12 & $<0.001$ \\
\hline No & $18(20.0)$ & $48(53.3)$ & $66(36.7)$ & & \\
\hline Total & $90(100.0)$ & $90(100.0)$ & $180(100.0)$ & & \\
\hline \multicolumn{6}{|c|}{$\begin{array}{l}\text { CEP attendance on malaria in the } \\
\text { last } 24 \text { months }\end{array}$} \\
\hline Yes & $55(76.4)$ & $20(47.6)$ & $75(65.8)$ & 8.52 & 0.004 \\
\hline No & $17(23.6)$ & $22(52.4)$ & $39(34.2)$ & & \\
\hline \multirow{2}{*}{\multicolumn{6}{|c|}{ Licence status of shop owner }} \\
\hline & & & & & \\
\hline Yes & $3(3.6)$ & $7(9.3)$ & $10(6.3)$ & & $0.193^{*}$ \\
\hline No & $81(96.4)$ & $68(90.7)$ & $149(93.7)$ & & \\
\hline Total & $84(100.0)$ & 75(100.0) & $159(100.0)$ & & \\
\hline \multicolumn{6}{|l|}{ Job status } \\
\hline Only job & $82(91.1)$ & $81(90.0)$ & $163(90.6)$ & 0.00 & 1.000 \\
\hline Main/Part-time job & $8(8.9)$ & $9(10.0)$ & $17(9.4)$ & & \\
\hline Total & $90(100.0)$ & $90(100.0)$ & $180(100.0)$ & & \\
\hline
\end{tabular}

Table 3: Findings from observation of patent medicine shops

\begin{tabular}{|c|c|c|c|c|c|}
\hline Variable & $\begin{array}{l}\text { Ikorodu group } \\
\text { Freq (\%) }\end{array}$ & $\begin{array}{l}\text { Ibeju-Lekki group } \\
\text { Freq (\%) }\end{array}$ & Total & $x^{2}$ & $P$-value \\
\hline \multicolumn{6}{|l|}{ Presence of sign post } \\
\hline Yes & $3(3.3)$ & $4(4.4)$ & $7(3.9)$ & & $1.000^{*}$ \\
\hline No & $87(96.7)$ & $86(95.6)$ & $173(96.1)$ & & \\
\hline Total & $90(100.0)$ & $90(100.0)$ & $180(100.0)$ & & \\
\hline \multicolumn{6}{|l|}{ Wording in business } \\
\hline name & $1(33.3)$ & $2(50.0)$ & $3(42.9)$ & & $1.000^{*}$ \\
\hline Patent medicines shop & $2(66.7)$ & $2(50.0)$ & $4(57.1)$ & & \\
\hline Others & $3(100.0)$ & $4(100.0)$ & $7(100.0)$ & & \\
\hline \multicolumn{6}{|l|}{ Total } \\
\hline \multicolumn{6}{|l|}{ Nature of shop } \\
\hline Drug shop only & $8(8.9)$ & $4(4.4)$ & $12(6.7)$ & 0.80 & 0.370 \\
\hline Drug shop/provision store & $82(91.1)$ & $86(95.6)$ & $168(93.3)$ & & \\
\hline Total & $90(100.0)$ & $90(100.0)$ & $180(100.0)$ & & \\
\hline \multicolumn{6}{|l|}{ Annual practising licence } \\
\hline $\begin{array}{l}\text { Displayed/presented on } \\
\text { request }\end{array}$ & $1(1.1)$ & $5(5.6)$ & $6(3.3)$ & 1.55 & 0.211 \\
\hline Not available & $89(98.9)$ & $85(94.4)$ & $174(96.7)$ & & \\
\hline Total & $90(100.0)$ & $90(100.0)$ & $180(100.0)$ & & \\
\hline \multicolumn{6}{|l|}{ Status of licence } \\
\hline Expired & $1(100.0)$ & $3(60.0)$ & $4(66.7)$ & & 1.000 \\
\hline Not expired & $0(0.0)$ & $2(40.0)$ & $2(33.3)$ & & \\
\hline Total & $1(100.0)$ & $5(100.0)$ & $6(100.0)$ & & \\
\hline
\end{tabular}


Table 4: Types of antimalarial drugs found in the observed patent medicine shops

\begin{tabular}{|c|c|c|c|c|c|}
\hline Antimalarial & $\begin{array}{l}\text { lkorodu } \\
\text { group } \\
\text { n=90 } \\
\text { Freq (\%) }\end{array}$ & $\begin{array}{l}\text { Ibeju-Lekki } \\
\text { group } \\
\text { n=90 } \\
\text { Freq (\%) }\end{array}$ & $\begin{array}{l}\text { Total } \\
\mathrm{n}=180 \\
\text { Freq (\%) }\end{array}$ & $\mathrm{x}^{2}$ & $p$ \\
\hline ACTs & $39(43.3)$ & $67(74.4)$ & $106(58.9)$ & 16.73 & $<0.001$ \\
\hline $\begin{array}{l}\text { Artemisinin } \\
\text { monotherapies }\end{array}$ & 66 (73.3) & 70 (77.8) & $136(75.6)$ & 0.27 & 0.603 \\
\hline Chloroquine & 80 (88.9) & 87 (96.7) & $167(92.8)$ & 2.98 & 0.084 \\
\hline Amodiaquine & 17 (18.9) & $10(11.1)$ & $27(15.0)$ & 1.57 & 0.210 \\
\hline $\begin{array}{l}\text { Sulphadoxine- } \\
\text { pyrimethamine }\end{array}$ & $81(90.0)$ & 77 (85.6) & $158(87.8)$ & 0.47 & 0.495 \\
\hline Quinine & $4(4.4)$ & $7(7.8)$ & $11(6.1)$ & 0.39 & 0.534 \\
\hline Pyrimethamine & $3(3.3)$ & $10(11.1)$ & $13(7.2)$ & 2.98 & 0.084 \\
\hline Halofantrine & $2(2.2)$ & $10(11.1)$ & $12(6.7)$ & 4.38 & 0.036 \\
\hline Others & $0(0.0)$ & $3(3.3)$ & $3(1.7)$ & & $0.246^{*}$ \\
\hline
\end{tabular}

${ }^{*}$ Fisher exact $p$-value

\section{Observational findings on drug shops}

Only seven (3.9\%) shops had sign-post announcing their premises and only three out of the seven contained the required wordings. Of all, only six $(3.3 \%)$ of the stores had the shop owners' annual practising license conspicuously displayed or presented on request. Majority of the shops surveyed functioned as both a drug shop and a provision store (Table 3). All the antimalarials examined had NAFDAC number and none had expired.

Different types of antimalarials were stocked in both areas (Table 4). "Others" were herbal products called "M \& T" capsule labeled as "...for malaria treatment" and carried NAFDAC number. In only one shop was an injectable antimalarial (quinine) found.

\section{DISCUSSION}

This study describes the people operating as PMVs in rural Lagos and reports their status as regards compliance with regulatory bodies' (PCN and NAFDAC) guidelines. Other studies in Nigeria found a lower proportion of respondents as shop owners $[10,14]$. This may be attributable to the fact that running the shop was the only source of income for most of the PMVs in this study as opposed to the cited studies where respondents had other sources of income. The finding of apprentices or sales attendants selling antimalarials calls for concern. They may not have adequate knowledge of malaria treatment compared to the shop owners and may not be able to sell appropriate drugs in the correct doses to their clients, a practice that may result in poor treatment with consequences such as recrudescence, drug resistance, progression from uncomplicated to severe malaria and ultimately avoidable death. This finding also shows that any capacity building programme for
PMVs may be more effective if apprentices and sales attendants are involved since they interface with clients in a number of shops. The finding of respondents younger than 21 years was due to the participation of apprentices and sales attendants. When both were excluded from the data, the age range was 22 - 67 years. This complies with PCN's minimum requirement of 21years for a PMV to be licensed [8]. Maturity is essential in the business as a PMV is not just a seller; s/he needs to counsel clients and often has to make treatment decisions for them, a task that can only be successfully performed by an adult.

About a third of the PMVs in the study had previous health-related training. This proportion is higher than that found in other studies in Nigeria [14-16], but much lower than what was reported in studies in Tanzania where 93-97\% of PMVs had formal health training $[6,17]$. This disparity is not unexpected as it is mandatory for PMVs in Tanzania to have formal health training before they can be licensed to practise [6], while in Nigeria the educational requirement is just being able to read and write in English language [8]. Basic health training would no doubt expose PMVs to rudiments of malariology and the understanding of other common ailments including the basic pharmacology of drugs meant to treat those ailments, thus enhancing appropriate treatment.

For majority of the vendors, operating their drug shops was their only business. The study in Kaduna, Nigeria also reported a high figure of about $80 \%$ operating their shops as their sole business [14]. Organizing a programme that would enhance the malarial treatment practice and increase patronage and sales by PMVs would probably have a great appeal since their shops were the only business concern most of them had. At the same time since most of them 
were shop owners, it might be difficult to call them out for long sessions of training. This should be factored into any training that would be organized for them; multiple short sessions rather than long sessions would probably yield better result. $[18,19]$

About two-thirds of the PMVs attended some form of continuing education programme (CEP) in the previous two years - a prerequisite for licence renewal by the PCN [8]. It is the duty of the PCN to organize such CEPs for licensed PMVs [8], but since majority of the PMVs were unlicensed, PCN could not have been the organizer of the attended CEPs. This implies that the largely unlicensed PMVs had not been officially exposed by the regulatory body to any formal lecture/training to improve their practice in the last two years prior to data collection, despite new policies and developments in the management of some of the common ailments for which they are consulted by the community. For malaria, less than half of the PMVs had attended at least one CEP. Some of the programmes attended, especially those organized by pharmaceutical companies, may just be drug presentations where adequate knowledge about the disease may not be passed. This underscores the importance of government taking the lead in organizing CEPs for both licensed and unlicensed PMVs. If the PCN has failed in stopping unlicensed PMVs from operating, it will be disastrous to pretend they do not exist and exclude them from orientation and education programmes that can enhance their contribution to appropriate malaria treatment.

There was worrisome violation of guidelines set by the PCN for operating as a PMV and for owning a drug shop. An insignificant number had a sign-post and out of those that had, only a few carried the prescribed wordings. Without a signpost it would be difficult for the PCN and other legal and relevant agencies that may want to monitor their activities to identify their business premises. Almost all the vendors were operating without practising license from the PCN. Many claimed they had applied and were in the process of being licensed. As explained by officers of the association in a preliminary discussion with them, the licensing process is long and may take several months or years. There was a long period when issuance of licence to PMVs was suspended because of conflict among the stakeholders in the regulation of their practice [20]. This could partly explain why most of them did not have licence. Nonetheless, the fact that many of them had been in practice for many years without licence (not even expired one) reflects a weak enforcement by the PCN. A similar study among PMVs done in Kaduna, Nigeria reported a much higher figure of $56 \%$ displaying their licenses, though the status of the licences was not mentioned [14]. The PMVs in the Kaduna study belonged to NAPPMED (we worked with LSMDA members), a parallel body of PMVs. Could there be a fundamental difference in the way both bodies comply with rules? Unlicensed businesses are more difficult to regulate and this creates room for malpractices and corruption. Infringements of this kind are common with vendors as studies in Tanzania and Uganda showed similar violations $[6,17]$. In the study in Tanzania, 11 of the 30 shops studied lacked valid permit and none of the serving drug sellers met the qualification requirements for practising [6]. In Uganda, only $39 \%$ of the drug shops were registered [21].

In this study, all the drugs checked were duly registered, none had expired and there was almost a universal absence of injectable antimalarials. This contrasts with findings from similar studies in Tanzania where $63 \%$ stocked unregistered and 13\% stocked expired antimalarials [6], and in Kenya where many unapproved and unregistered antimalarials were found and less than half of the recommended ones were registered [7]. Absence of unregistered or expired antimalarials in the observed shops was some evidence that the ongoing campaign against counterfeit drugs by NAFDAC was yielding result. Alternatively, could it be due to concealment of incriminating drugs by PMVs as has been reported in an earlier study [6]?

Chloroquine (CQ) and sulphadoxinepyrimethamine (SP), the former first and second line AMDs had the lion's share of the market despite that they are no longer recommended except SP that is reserved for intermittent preventive treatment of malaria in pregnancy (IPTp) [9]. CQ and SP were replaced because of their reduced effectiveness occasioned by resistance of malaria parasite to them. Their dominance in drug shops means people are still exposed to inadequate treatment with consequences. Another worrisome finding was the wide availability of artemisinin monotherapies. The WHO recommended their withdrawal from the market because of evidence of resistance to them and the danger they pose to the ACTs [22]. Immediate withdrawal of these drugs and other non-artemisinin monotherapies, particularly $C Q$ ad SP should be pursued with vigour. 


\section{Limitations of the study}

As noted earlier, the zone in Ikorodu LGA was purposively selected and might theoretically not be representative of the entire LGA. However, there is little doubt that it is similar in all respect to the other zones as they shared the same modus operandi being in the same LGA. NAPPMED members were not involved in the study. This limits generalization of the findings to all vendors in the reference population.

\section{CONCLUSION}

This study shows poor compliance with regulatory guidelines and some significant differences of programmatic importance between the two study LGAs, even though both are rural. The ubiquitousness of PMVs can help to get ACTs to remote areas where formal heath care providers may not be present. However, given their poor compliance with some regulatory guidelines and the consequences of this for malaria treatment in the communities, there is a need for the authorized government agency to redouble its effort to enforce compliance and supervise their activities. Government should revise the list of antimalarials PMVs are permitted to sell to reflect the policy change and prevent the sale of ineffective antimalarials.

\section{ACKNOWLEDGEMENT}

Many thanks to the executive members of LSMDA at the state and LGA levels, and to all the patent medicine vendors who participated in the study.

\section{REFERENCES}

1. Goodman C, Brieger W, Unwind A, Mills A, Meek $S$, Greer $G$. Medicine sellers and malaria treatment in Sub-Saharan Africa: what do they do and how can their practice be improved? Am J Trop Med Hyg 2007; 77(Suppl 6): 203-218.

2. Salako LA, Brieger WR, Afolabi BM, Umeh RE, Agomo $P U$. Treatment of childhood fevers and other illnesses in three rural Nigerian communities. J Trop Pedia 2001; 47: 230-238.

3. Okonkwo AD, Okonkwo UP. Patent medicine vendors, community pharmacists and STI management in Abuja, Nigeria. Afri Health Sci 2010; 10: 253-265.

4. Aniebue PN, Aguwa EN, Obi El. Universal Precautions: awareness and practice of patent medicine vendors in Enugu metropolis, South East Nigeria. Niger Med J. 2010; 51: 30-34.

5. Federal Ministry of Health/World Health Organization. National Drug Policy, First Revision 2003.

6. Goodman $C$, Kachur SP, Abdulla S, Bloland P, Mills A. Drug shop regulation and malaria treatment in
Tanzania-why do shops break the rules, and does it matter? Health Policy Plan 2007; 22: 393-403.

7. Amin $A A$, Snow RW. Brands, costs and registration status of antimalarial drugs in the Kenyan retail sector. Malar J 2005; 4: 36.

8. Pharmacists Council of Nigeria. Guidelines on the issuance of Patent and Proprietary Medicines Vendor's License. 2003.

9. Federal Ministry of Health, National Malaria and Vector Control Division, Abuja-Nigeria. National Antimalarial Treatment Policy. February 2005.

10. Federal Ministry of Health, National Malaria and Vector Control Division, Abuja-Nigeria. National Antimalarial Treatment Guidelines. May 2005.

11. UNICEF. Malaria and children: Progress in intervention coverage. [cited 2009 Jun 3]. Available from: http://www.unicef.org/media/files/WMD_optimized_ reprint.pdf

12. National Population Commission (NPC) [Nigeria] and ICF Macro. Nigeria Demographic and Health Survey 2008. Abuja, Nigeria: National Populaton Commission and ICF Macro 2009.

13. Varkevisser CM, Pathmanathan I, Brownlee $A$. Designing and Conducting Health Systems Research Projects. International Development Centre Ottawa and WHO Geneva. Vol.2: 216.

14. Akuse RM, Eseigbe EE, Ahmed A, Brieger WR. Patent medicine sellers: how can they help control childhood malaria? Malar Res Treat 2010, Article ID 470754, 7 pages.

15. Jimmy EO, Achelonu E, Orji S. Antimalarials dispensing pattern by patent medicine dealers in rural settlements in Nigeria. Public Health 2000; 114: 282-285.

16. Okeke TA, Uzochukwu BSC. Improving childhood malaria treatment and referral practices by training patent medicine vendors in rural south-east Nigeria. Malar J 2009; 8: 260.

17. Hetzel MW, Dillip A, Lengeler C, Obrist B, Msechu JJ, Makemba AM, Mshana C, Schulze A, Mshinda $H$. Malaria treatment in the retail sector: knowledge and practices of drug sellers in rural Tanzania. BMC Public Health 2008; 8: 157.

18. Greer G, Akinpelumi A, Madueke L, Plowman B, Fapohunda B, Tawfik $Y$, Holmes R, Owor J, Gilpin $U$, Clarence $C$, LennoxB. Improving Management of Childhood Malaria in Nigeria and Uganda by Improving Practices of Patent Medicine Vendors. Arlington, VA.: BASICS II for the United States Agency for International Development. 2004.

19. Brieger $W$, Salako L, Umeh $R$, Agomo $P$, Afolabi B, Adeneye A. Promoting prepackaged drugs for prompt and appropriate treatment of febrile illnesses in rural Nigerian communities. Int $Q$ Community Health Educ 2002; 21: 19-40.

20. Oladepo O, Salami KK, Adeoye BW, Oshiname F, Ofi B, Oladepo M, Ogunbemi O, Lawal A, Brieger WR, Bloom G, Peters DH. Malaria treatment and policy in three regions in Nigeria: the role of patent medicine vendors. [cited 2008 Jul 20]. Available from: www.futurehealthsystems.org/publications/ WP1\%20final.pdf.

21. Tawfik Y, Nsungwa-Sabitii J, Greer G, Owor J, Kesande $R$, Prysor-Jones S. Negotiating improved case management of childhood illness with formal and informal private practitioners in Uganda. Trop Med Int Health 2006; 11: 967-973.

22. World Health Organization. World Malaria report 2011. Switzerland: World Health Organization; 2011. 